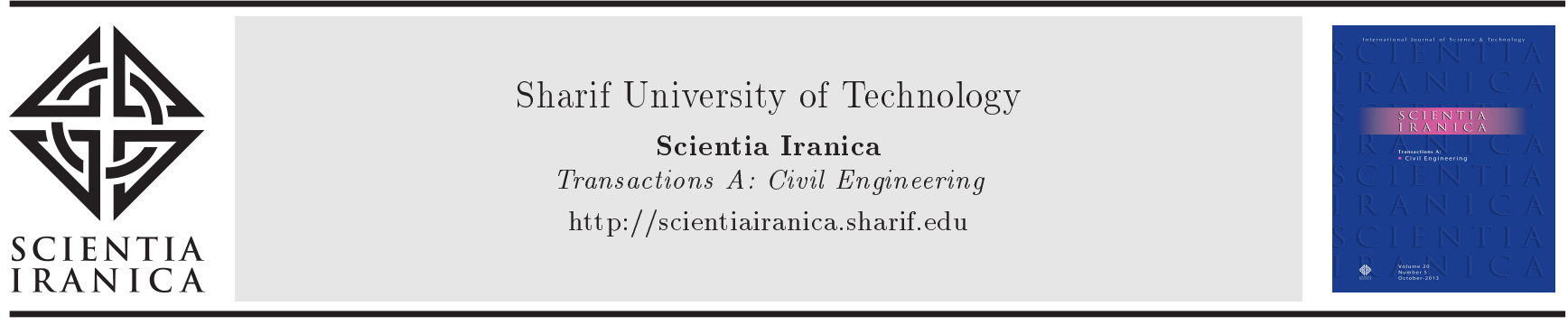

Research Note

\title{
Evaluation of the effects of stirrup spacing and buckling of steel reinforcing bars on the capacity of RC columns
}

\author{
S.Sh. Hashemi*, M. Vaghefi, and M. Hemmat \\ Civil Engineering Department., Persian Gulf University, Bushehr, Iran.
}

Received 13 October 2015; received in revised form 7 September 2016; accepted 21 November 2016

KEYWORDS
Buckling;
Reinforced concrete
column;
Stirrup;
Column capacity;
Bond-slip effect.

\section{Introduction}

Various numerical and analytical methods have been presented to estimate the capacity of $\mathrm{RC}$ sections. The interaction between reinforcing steel bars and surrounding concrete should be considered appropriately through the process of capacity estimating. The reinforcing bars are usually subjected to tensile or compressive forces in $\mathrm{RC}$ sections. With regards to circumstances, the compressive longitudinal bars in interaction with the concrete segment are prone

\footnotetext{
*. Corresponding author. Tel.: + 9877 31222150;

Fax: + 98 rry 31540376

E-mail addresses: sh.hashemi@pgu.ac.ir (S.Sh. Hashemi);

vaghefi@pgu.ac.ir (M. Vaghefi);

mehdihemmat88@gmail.com (M. Hemmat)
}

to buckling. Currently, according to the methods recommended by building codes, on the one hand, it is assumed that the probable buckling is prevented by observing the required provisions. Hence, the effect of steel bars buckling is not considered [1]. On the other hand, building codes would prevent buckling by applying requirements for stirrups spacing, stirrups diameter, and concrete cover. If these requirements are not observed thoroughly in an $\mathrm{RC}$ member, the buckling is likely to occur. Clear statement of the eventual capacity reduction compared with codes requirements in this regard is needed. Many researches have been conducted on the buckling of longitudinal reinforcement bars. These researches are classified in two major categories of those on the buckling action of bars and those on the effect of buckling on the nonlinear behavior of RC sections. Various models based on the stress-strain curve of 
steel bar have been presented for numerical modeling of buckling behavior, including simple models such as the Gomes and Appleton model in 1997 [2] and complicated models such as the models by Berry and Eberhard in 2005 [3], Bae and Mises in 2005 [4], Zong and Kunnath in 2008 [5], Dhakal and Maekawa in 2002 [6], Masonne and Moroder in 2009 [7], and Kashani and Crewe in 2013 [8]. The model proposed by Appleton and Gomes (1997) is simple and consistent with the G-M-P stress-strain model by Giuffre and Pinto in 1970 [9]. The majority of the second group study the numerical investigation of nonlinear behavior of, particularly, post-yield zone and the effects of buckling on ductility in RC sections. In addition, various experimental methods along with simple to micro modeling numerical methods, for instance, the models by Lukkunaparasit et al. [10], Lopes et al. [11], and Potger et al. [12], have been used by researchers.

Despite the extensive researches in the field of steel bar buckling in RC sections, the aim of this paper is to study the effects of bar buckling on the capacity of RC sections as well as on the interaction curves of axial load-bending moment capacity proposed by codes, which have not been fully considered in previous studies. Based on the obtained results of this research, it is feasible to estimate the strength capacity of $\mathrm{RC}$ sections regarding the possibility of steel bars buckling when the requirements for the stirrups spacing are not properly met. Moreover, an appropriate definition exists for the capacity of RC members with the probable buckling of compressive steel bars, which can lead engineers to a suitable process for the seismic retrofitting design of existing old RC structures.

\section{Theory of research}

An exerted cyclic loading on $\mathrm{RC}$ sections might take the compressive steel bar behavior to the nonlinear zone. The buckling behavior of steel bars depends on the ratio of stirrups spacing $\left(L_{s}\right)$ to diameter of the bar $\left(d_{b}\right)$, which is defined by slenderness ratio. The stress-strain relationship is presented for some slenderness ratios in Figure 1. For low slenderness, the effect of buckling is not observed and cycles show an expansion due to the effect of isotropic hardening; but, for higher slenderness, cycles are more contracted under the effect of buckling and the load gradient is reduced in compression.

After buckling, the stiffness of bar element in compression is considered on the basis of bending behavior [13]. Some researchers have recommended considering the buckling of the longitudinal bars based on the distance between two consecutive stirrups. In this distance, longitudinal bar is modeled as a fixed-end column [14]. According to a number of experimental and theoretical results, compressive bars are vulnerable to buckle in an equal length or longer distance between two consecutive stirrups [15]. Ideas have been provided by many researchers about the definitions in which the bar buckling must be taken into consideration. When some or all parts of surrounding concrete of the steel bars lose their strength and are crushed, or the stress in stirrups reaches the yield limit, the effect of bar buckling should be investigated [16].

Currently, ACI code gives an estimate of the nominal strength capacity of RC sections by benefiting from simplifying assumptions such as linear strain distribution along the height of section, neglecting shear deformations, and assuming perfect bond between longitudinal bars and concrete. Moreover, ACI estimates the ultimate capacity by applying reduction coefficients to the nominal capacity. On the other hand, ACI code gives some restrictive criteria on stirrups, which show differences for different levels of ductility and different sections and positions for the member [17]. One of the restrictive and determinant factors is limiting the stirrup transverse spacing to at most 6 times the diameter of the main bars. In the case of buckling of a bar, the effect of this provision is directly considered in the stress-strain relationship of the longitudinal bars as increase in slenderness of the bar intensifies the buckling effect.

\section{Numerical modeling}

Two types of elements have been used for numerical modeling of the examined column. The beam-column element is basically used for modeling the column together with the joint element applied for footing connection. In the method used on the basis of layered model, the assumption of perfect bond between concrete and bar has been neglected and the possible effects of slip have been considered [18]. In the joint
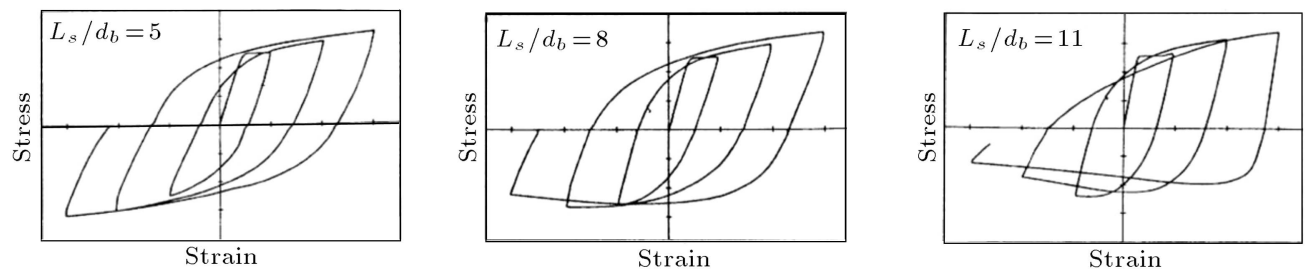

Figure 1. The effect of buckling on the stress-strain behavior of bars in different slenderness ratios [13]. 
element, the effect of pull-out can be considered as the relative displacement between the steel bar and surrounding concrete and bond stress is referred to as the shear stress acting parallel to an embedded steel bar on the contact surface between the reinforcing bar and concrete. The number of degrees of freedom on the side of the joint element is compatible with the degrees of freedom at the ends of the column elements adjacent to the joint element. Although it is feasible to model the pull-out effects, the embedded length of steel bars has been considered sufficiently large to prevent interference of bar's pull-out from the foundation in the results of this research [19].

The free body diagram of an infinitesimal segment, $d x$, of an RC column with internal and external forces is shown in Figure 2. As the element consists of two major parts of concrete and steel bar, the equilibrium relationships of internal forces have been written during discretization. The effect of bond force between the concrete and each longitudinal bar has been taken into calculation.

The axial equilibrium in the concrete element and steel bar $i$ is given by Eqs. (1) and (2):

$$
\begin{aligned}
& \frac{d N_{C}(x)}{d x}+\sum_{i=1}^{n} D_{b i}(x)=0, \\
& \frac{d N_{i}(x)}{d x}-D_{b i}(x)=0, i=1,2, . ., n,
\end{aligned}
$$

where:

$N_{C}(x) \quad$ The axial force in the concrete segment,

$N_{i}(x) \quad$ The axial force in the steel bar $i$,

$n \quad$ The number of longitudinal bars,

$D_{b i}(x) \quad$ The bond force between the concrete segment and bar $i$ per unit length.

Eq. (3) is provided based on the Euler-Bernoulli theory and the moment equilibrium about the $z$ axis of the cross section:

$$
\frac{d^{2} M_{z}(x)}{d x^{2}}-P_{y}(x)-\sum_{i=1}^{n} y_{i} \frac{d D_{b i}(x)}{d x}=0,
$$

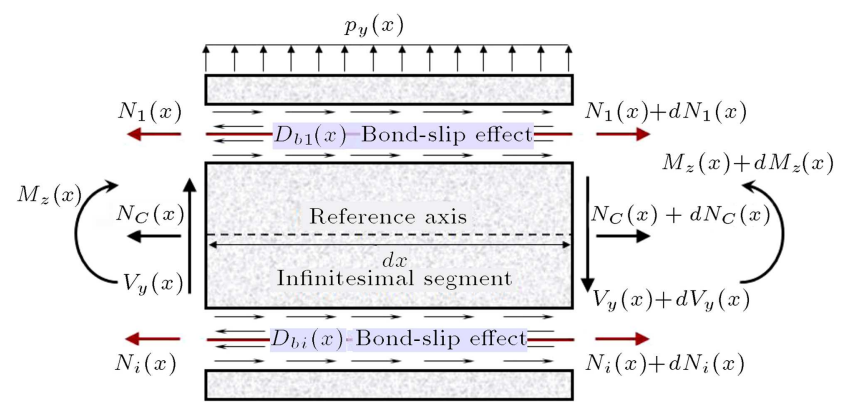

Figure 2. Free body diagram of infinitesimal segment of $\mathrm{RC}$ column. where:

$p_{y}(x) \quad$ Uniform external force on the element,

$M_{z}(x) \quad$ Bending moment,

$y_{i} \quad$ Bar distance from reference axis.

The slip between the longitudinal bars and the surrounding concrete in each section for the longitudinal position $x$ of reinforced concrete elements can be defined by Eq. (4):

$$
u_{b i}(x)=u_{i}(x)-u_{1 C}(x)+y_{i} \frac{d u_{2 C}(x)}{d x},
$$

where:

$$
\begin{aligned}
& u_{i}(x) \quad \begin{array}{l}
\text { The longitudinal displacement of bar, } \\
u_{1 C}(x) \quad \text { The longitudinal displacement of } \\
\text { concrete segment, }
\end{array} \\
& u_{2 C}(x) \quad \begin{array}{l}
\text { The transverse displacement of } \\
\text { concrete segment in the } y \text { axis } \\
\text { direction. }
\end{array}
\end{aligned}
$$

The weak form of displacement based finite element formulation is determined through the principle of stationary potential energy. A computer program created in MATLAB software has been used by the authors [20]. More details about the calculation of element have previously been provided elsewhere $[18,19]$. The number of degrees of freedom in a reinforced concrete element depends on the number of longitudinal bars. As an example, 14 degrees of freedom relates to a reinforced concrete element with 4 longitudinal bars. Six degrees is associated with the concrete segment and the others are for the bars.

The Newton-Raphson algorithm has been used for numerical nonlinear solving of equations. Each $\mathrm{RC}$ column element has been divided into elements with shorter length in order to consider the effects of dependency on the length of element, because the formulation is displacement based and the response depends on element size. As a simple suggestion, the length of the column elements can be selected equal to or shorter than the average flexural crack spacing in the column. Therefore, in this study, the flexural crack spacing is calculated based on the CEB (1978) and the column element is subdivided into a suitable number of shorter elements [21]. In these cases, convergence of the calculated responses will be achieved in the numerical process.

Yassin model is used for modeling the concrete stress-strain behavior (Figure 3). Tensile behavior has been considered to be bilinear and the effect of element size on tensile hardening has been considered [22]. Furthermore, the interaction effect between steel bar and concrete has been entered into calculations as the bond stress-slip relationship based on the Eligehausen model (Figure 4). This model is simple and has 


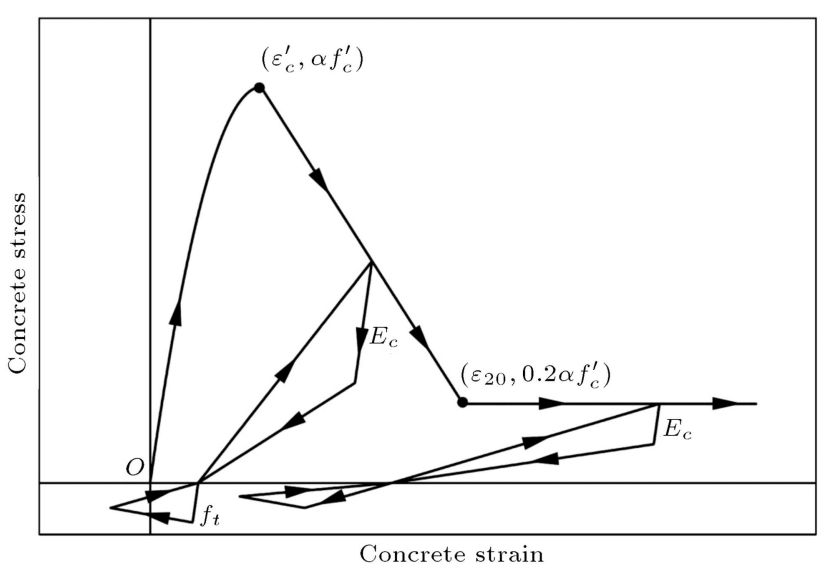

Figure 3. The stress-strain behavior of concrete based on the Yassin model [22].

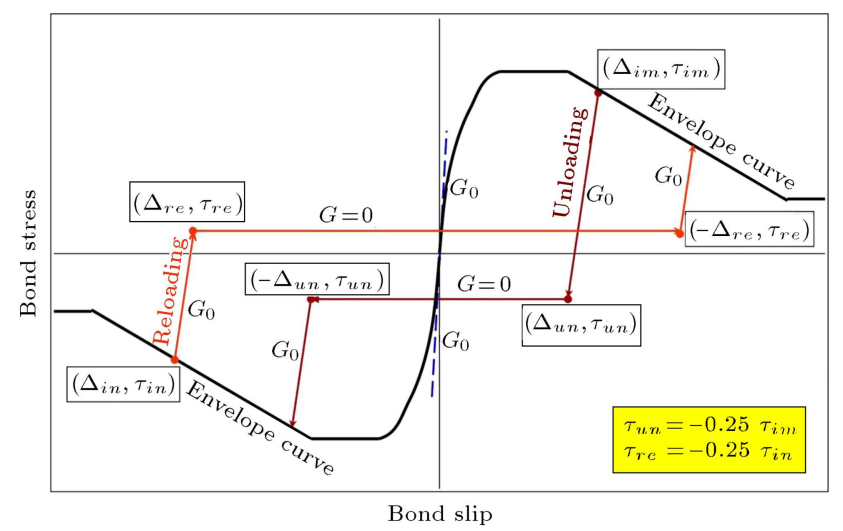

Figure 4. The bond stress-slip behavior based on the Eligehausen model [23].

shown good accuracy in modeling effective parameters compared to the other models [23]. In this model, the effects of many variables, such as spacing and height of lugs on the steel bar, concrete compressive strength, thickness of concrete cover, steel bar diameter, and end bars hook, are considered.

\section{Modeling of steel bar behavior and the effect of buckling}

The Giuffre-Menegotto-Pinto (G-M-P) model (1970) has been used in order to represent the stress-strain relationship of steel bars. The enveloping curve in Figure 5 presents a transform from a straight line with a slope of $E_{0}$ into another straight line with a slope of $E_{1}$. In this figure, the superscripts " 1 " and "2" respectively indicate the directions of loading and unloading, and $\left(\varepsilon_{s 0}, \sigma_{s 0}\right)$ is the coordinates of the asymptote's intersection point.

The model proposed by Gomes and Appleton has been employed to apply the effect of bar buckling in G-M-P stress-strain relationship. Based on the theory of this model, the process of checking the balance in a

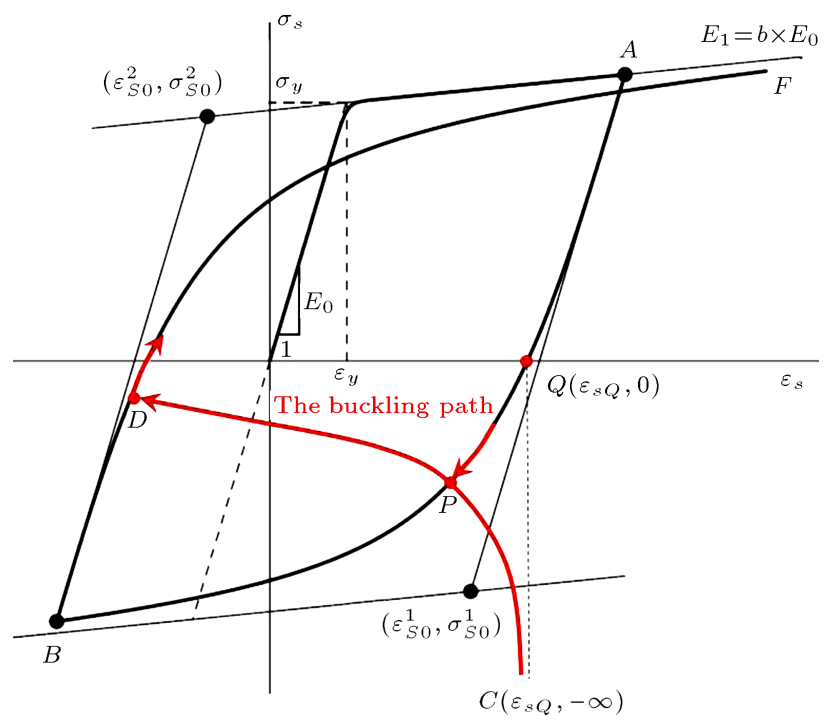

Figure 5. The stress-strain behavior of steel bar without buckling effect based on the G-M-P model.

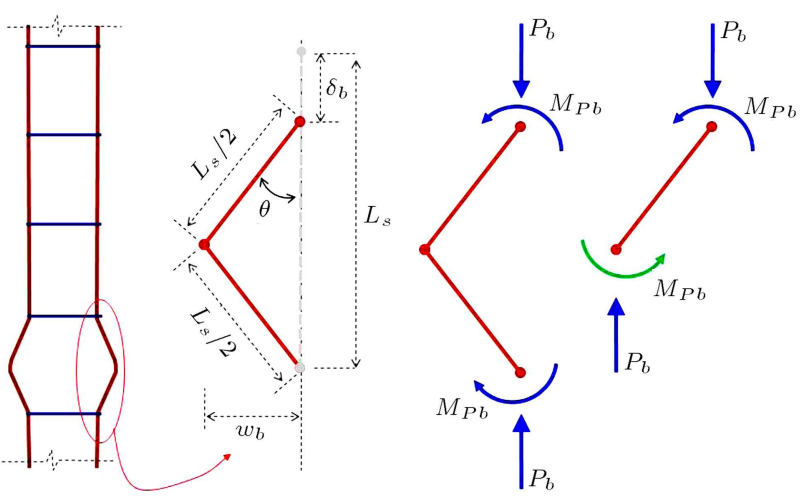

Figure 6. Free body diagram of buckling steel bar by Gomes and Appleton (1997) [2].

buckling bar between two stirrups has been depicted in Figure 6. Eq. (5) shows the stress-strain relationship in the buckling bar with regards to the details that have been explained by Gomes and Appleton (1997) [2]:

$$
\sigma_{s}=\left(\left(2 \sqrt{2} M_{P b}\right) /\left(A_{b} L_{s}\right)\right) / \sqrt{\varepsilon_{s}},
$$

where:

$A_{b} \quad$ Cross section of the steel bar,

$L_{s} \quad$ Effective length in buckling, which is considered equal to the distance between two consecutive stirrups,

$M_{p b} \quad$ Steel bar's plastic moment, which is calculated based on Eq. (6) for a circular cross section without axial load:

$$
M_{P b}=Z_{P} \times \sigma_{y}=0.424 \pi \times \frac{1}{8} d_{b}^{3} \times \sigma_{y},
$$

where: 
$Z_{p} \quad$ Plastic modulus of circular cross section,

$d_{b} \quad$ Bar's diameter.

In order to use Eq. (5) in stress-strain curve of the steel bars, the strain corresponding to the zero stress (the intersection point of the strain axis) should be determined (Figure 5$)$. This point $\left(\varepsilon_{S Q}, 0\right)$ is assumed as the origin of the curve coordinate and the change of variable $\varepsilon_{s n}=\varepsilon_{s}-\varepsilon_{S Q}$ is performed in Eq. (5). It is capable to consider the effect of axial force on buckling behavior of steel bars. The lack of this consideration is significant in small amounts of strain, but not impressive in nonlinear behavior and larger amounts of strain, in which the inclusion of bending moment effects of steel bar is sufficient. Hence, this study does not include the effect of interaction between axial force and bending moment to avoid complicated calculations.

During the modeling of RC elements, the effect of buckling in each steel bar is considered after crushing of the surrounding concrete. The point $(\mathrm{P})$ in Figure 5 is formed by intersection of compressive loading path (AB) and the curve of buckling effect (CD). An iterative process is necessary while reverse loading to determine the point (B) and, consequently, the position of point (D).

\section{Numerical analysis and method validation}

Validity of the proposed numerical method has been demonstrated through numerical and experimental results of the verification of two examined specimens. In this paper, the examined model by Kostantakopoulos and Bousias (2004) [24] is used and the numerical and experimental results are compared. Two columns with similar characteristics, except for the distance between stirrups, have been tested under lateral loading. The specimen with $L_{s}=4 d_{b}$ does not buckle, but another one with $L_{s}=12 d_{b}$ experiences the buckling of longitudinal steel bars. The cross section of specimens is square with dimensions of $250 \mathrm{~mm} \times 250 \mathrm{~mm}$ and height of $1600 \mathrm{~mm}$. Both specimens have 4 longitudinal steel bars with diameter of $16 \mathrm{~mm}$ and yield strength $\left(f_{y}\right)$ of $514 \mathrm{MPa}$. Moreover, the stirrups with diameter of $10 \mathrm{~mm}$ and yield strength of $542 \mathrm{MPa}$ are used. Finally, the concrete with compressive strength $\left(f_{c}\right)$ of $28 \mathrm{MPa}$ is conducted. A constant compressive axial load with a magnitude of $500 \mathrm{KN}$ is applied during the imposing of lateral cyclic load. More details on specimens are presented in the study by Kostantakopoulos and Bousias [24].

The numerical results for both specimens with and without buckling are presented and compared with experimental ones in Figures 7 and 8 . The results indicate high accuracy of the employed numerical

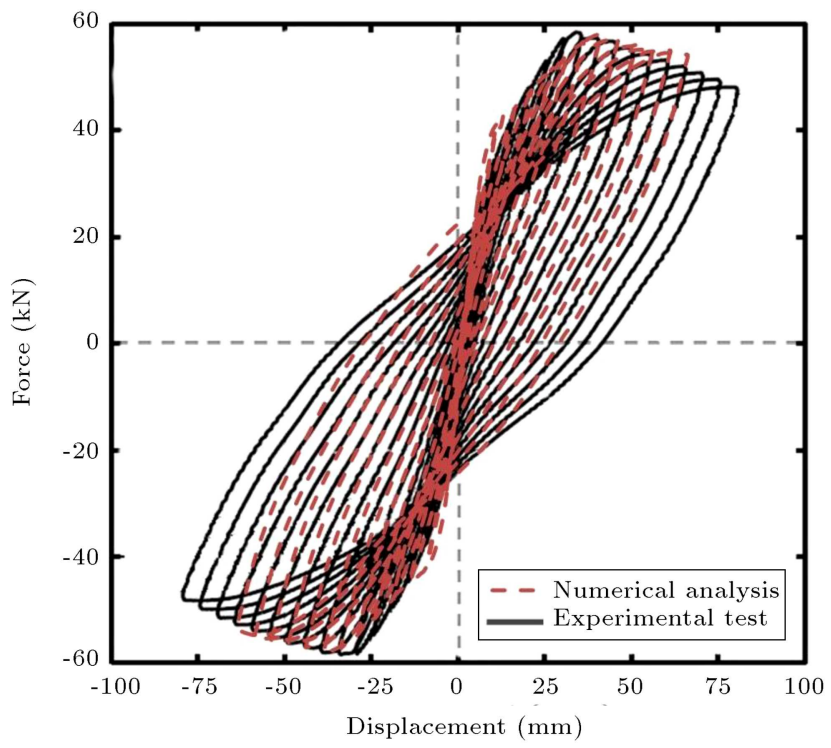

Figure 7. Experimental and numerical responses of the specimen with $L_{s}=4 d_{b}$ [24].

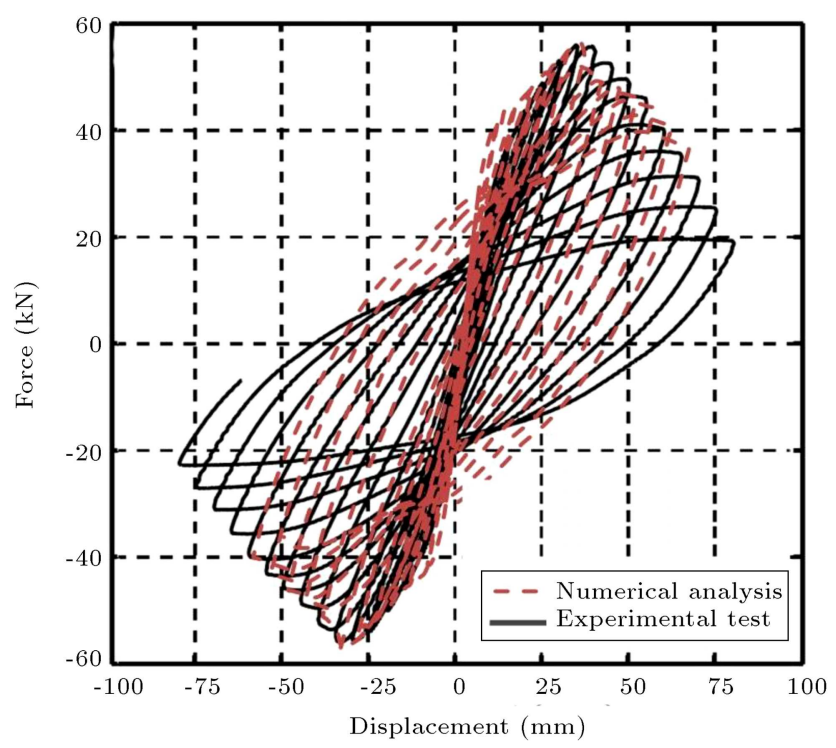

Figure 8. Experimental response of the specimen with $L_{s}=12 d_{b}[24]$.

method, especially in estimating the lateral capacity of columns. The history of the stress-strain curve for one of the steel bars is shown in Figure 9 in both cases of with and without buckling. Results show a significant difference in the behavior of steel bar in the presence of the buckling effect, especially in the case of experiencing deformation. For $L_{s}=12 d_{b}$, the confluence of the buckling curve and the envelop stressstrain curve of steel bar is located quite near the yield point $\left(\sigma_{y}\right)$. It shows that buckling does not have a significant role in reducing the compressive yield point of steel bar and is more effective on the post-yield range of behavior. This is justified by investigating the behavior of experimental and numerical specimens with 


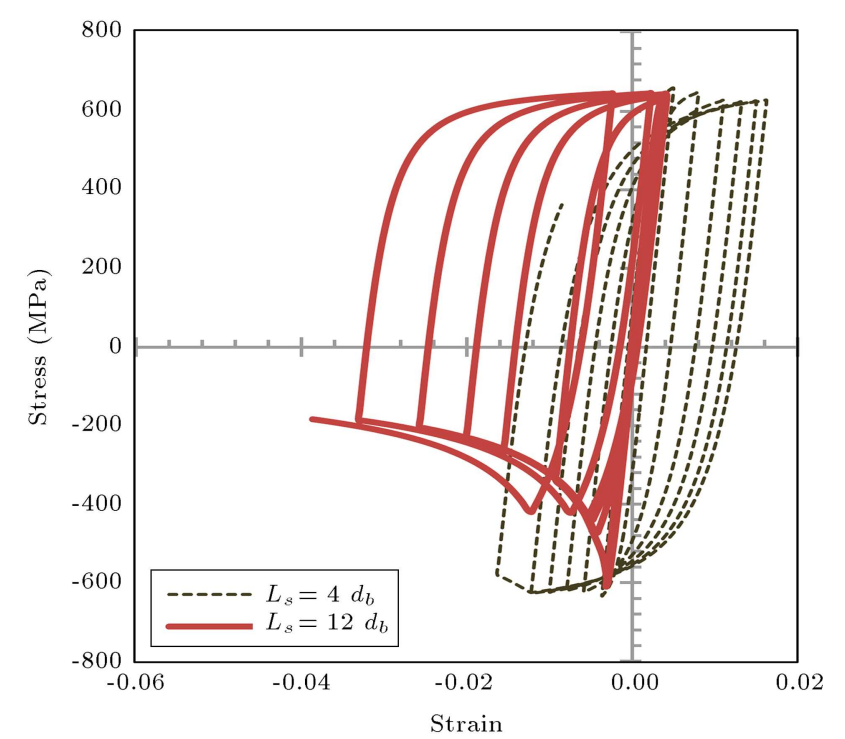

Figure 9. The steel bar behavior with and without buckling effect.

and without buckling. In other words, the ultimate strength capacities are almost identical in both of the examined specimens and the small disparity is due to the effect of $L_{s}$ on the coefficient of confined concrete. But, after yielding of the compressive steel bar, nonlinear behavior of specimen shows softening with high gradient as a result of buckling effect. Thus, experimental behavior is well predicted by numerical analysis.

\section{Numerical investigation}

In order to investigate the capacity of RC columns, various samples of short column, listed in Table 1 with fixed and variable characteristics, are modeled and analyzed. Thirty models have been investigated and the obtained results are compared with the capacity curves of ACI code. Models of this study have been selected based on the characteristics and geometry proposed in the laboratory research by Qui et al. [25]. The case study, i.e. the column with $50 \mathrm{~mm}$ stirrup spacing and $40 \mathrm{MPa}$ compressive strength for concrete, is tested under a constant $350 \mathrm{kN}$ axial load. Because good agreement is observed between the results of the numerical method and the experimental one, the results of this verification have not been mentioned to avoid prolongation of the text.

Many researchers have conducted numerical analyses to investigate the effect of buckling by monotonic and cyclic methods. Bae et al. in 2005, Dhakal and Maekawa in 2002, Monti and Nuti in 1992, and Mander et al. in 1994 [26] investigated the effect of buckling through both cyclic and monotonic analyses together. On the other hand, Zong and Kunnath in 2008, Mander in 1983 [27], and Bai et al. in 2012 [28] studied the buckling using monotonic analyses. Despite the fact that buckling effects of the bar are more obvious in cyclic behavior and large deformations, the pushover analysis has been used in this paper, since the main objective is to investigate the effect of buckling on the ultimate capacity. Therefore, there is no explicit and specific statement in regard to ductility, post-buckling, and post-yield of the bars.

The resulting axial force-bending moment interaction curves (P-M) are presented in Figure 10 along with the curves obtained from ACI code. The ACI P-M interaction curves have been plotted with and without capacity reduction factor $(\phi)$ (the ultimate and nominal capacities) in order to make a better comparison. Quantitative investigations are performed in 3 cases of pure bending, maximum bending capacity affected by the axial force-bending moment interaction, and pure axial force. Results are presented in Table 2.

Table 1. Fixed and variable properties of the specimens.

\begin{tabular}{|c|c|c|c|c|}
\hline \multicolumn{2}{|c|}{ Dimensions of models } & \multicolumn{3}{|c|}{$200 \mathrm{~mm}^{*} 200 \mathrm{~mm}$} \\
\hline \multicolumn{2}{|c|}{ Stirrup diameter } & \multicolumn{3}{|c|}{$6 \mathrm{~mm}$} \\
\hline \multicolumn{2}{|c|}{ Yield stress of longitudinal bars } & \multicolumn{3}{|c|}{$460 \mathrm{MPa}$} \\
\hline \multicolumn{2}{|c|}{ Yield stress of stirrup } & \multicolumn{3}{|c|}{$420 \mathrm{MPa}$} \\
\hline \multicolumn{2}{|c|}{ Thickness of concrete cover } & \multicolumn{3}{|c|}{$21 \mathrm{~mm}$} \\
\hline \multicolumn{2}{|c|}{ Variety in distances between stirrups } & \multicolumn{3}{|c|}{$(5,10,20,30,50) \times d_{b}$} \\
\hline Specimen ID & Stirrups spacing ( $\mathrm{mm})$ & Longitudinal bars & Percentage of bars, $r$ & $f_{c}(\mathrm{MPa})$ \\
\hline S1-1 & $50,100,200,300,500$ & $8 \mathrm{f} 10 \mathrm{~mm}$ & $1.57 \%$ & 30 \\
\hline S1-2 & & & & 40 \\
\hline $\mathrm{S} 2-1$ & $60,120,240,360,600$ & $8 \mathrm{f} 12 \mathrm{~mm}$ & $2.26 \%$ & 30 \\
\hline $\mathrm{S} 2-2$ & & & & 40 \\
\hline S3-1 & $60,120,240,360,600$ & $12 \mathrm{f} 12 \mathrm{~mm}$ & $3.39 \%$ & 30 \\
\hline S3-2 & & & & 40 \\
\hline
\end{tabular}



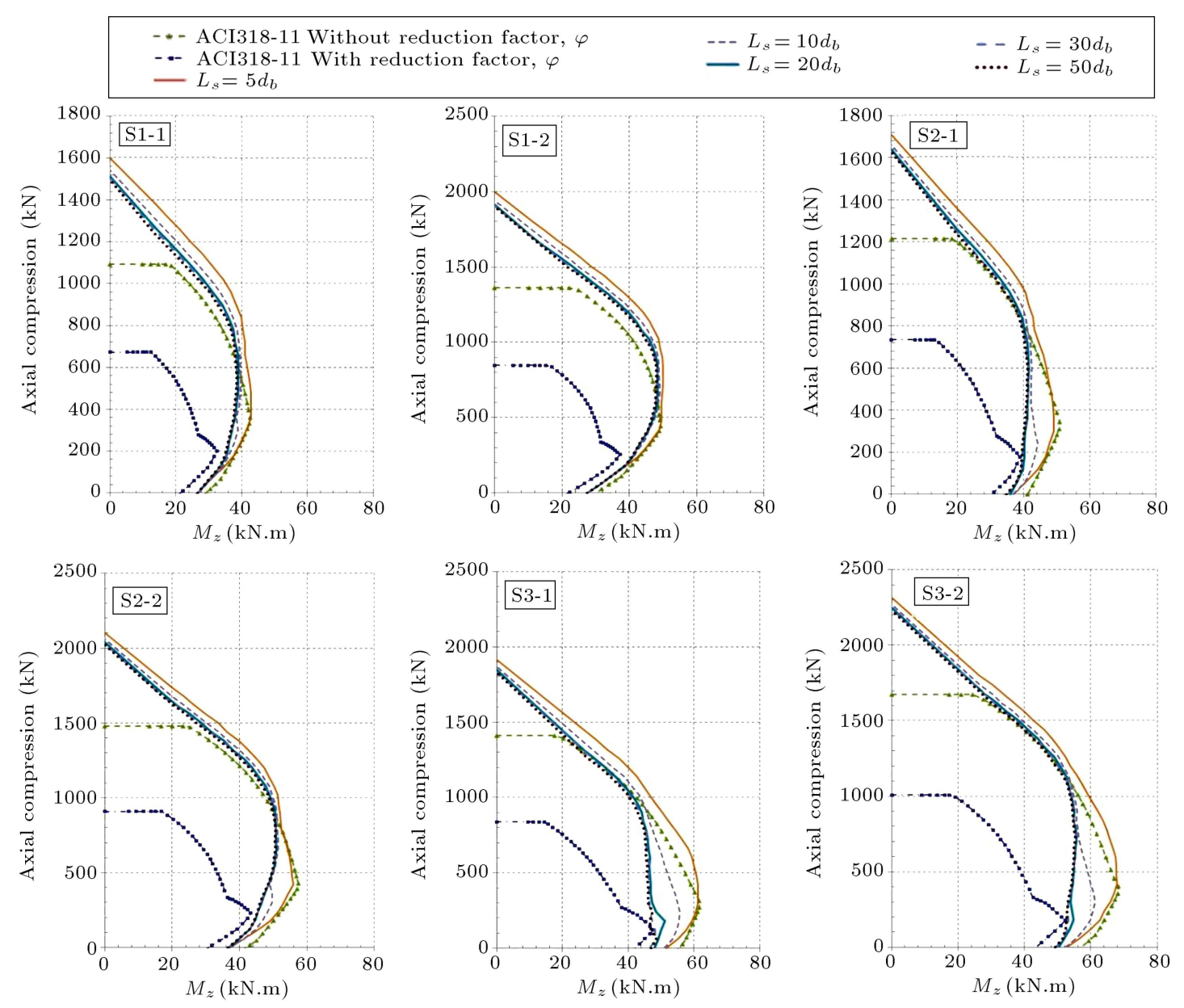

Figure 10. P-M curves of the specimens.

The results for the specimen with $L_{s}=5 d_{b}$, in which buckling does not occur, have been chosen as a criterion and the relative percent of disparity are presented for other specimens per increase in the stirrup spacing (Table 2).

\section{Discussion and interpretation of results}

Increasing the $L_{s}$ factor has two significant effects on numerical responses. One of them is reduction in confinement of the core concrete and the other one is exacerbation of the buckling potential of longitudinal bars. The effect of $L_{s}$ on the compressive strength of confined concrete is utilized in estimating the capacity as the confined coefficient factor, although this factor has been neglected in assessing the strength of concrete in codes as a conservative approach. By considering the equation of buckling path equal to the steel stressstrain envelope curve, an intersection point will be achieved that shows the condition in which the buckling point $\left(\varepsilon_{b}\right)$ and the yield point of curve $\left(\varepsilon_{s o}\right)$ are identical, as shown in Figure 11 and Eq. (7):

$$
L_{s}=0.6 \times \varepsilon_{s 0}^{-\frac{1}{2}} \times d_{b},
$$

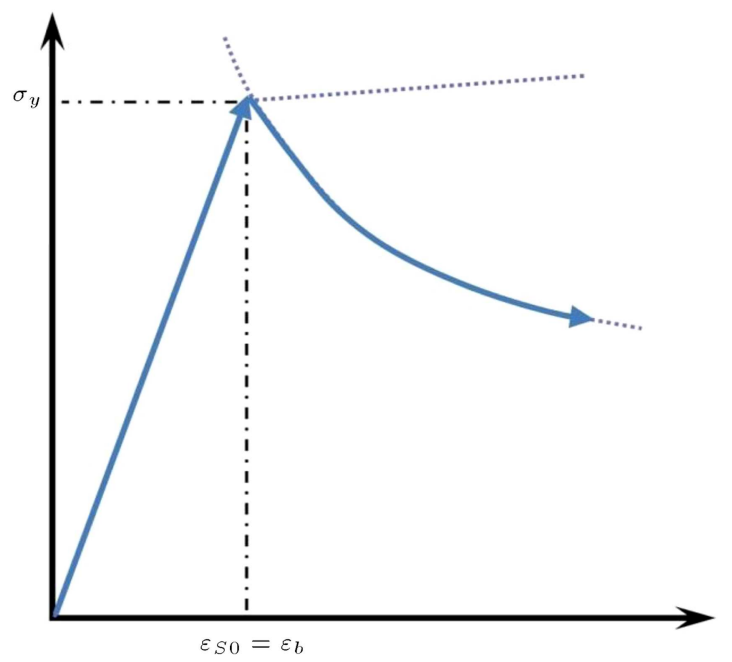

Figure 11. The behavior of compressive steel bar when $\varepsilon_{b}=\varepsilon_{S 0}$.

where $d_{b}$ is the bar diameter. This equation will be equal to $12.5 d_{b}$ for the cases under study. For greater amounts of $L_{s}$, buckling path and separation from the envelope curve are considered before the theoretical yield point of the bar $\left(\sigma_{y}\right)$. On the other hand, if $L_{s}$ 
Table 2. Capacity evaluation of the specimens.

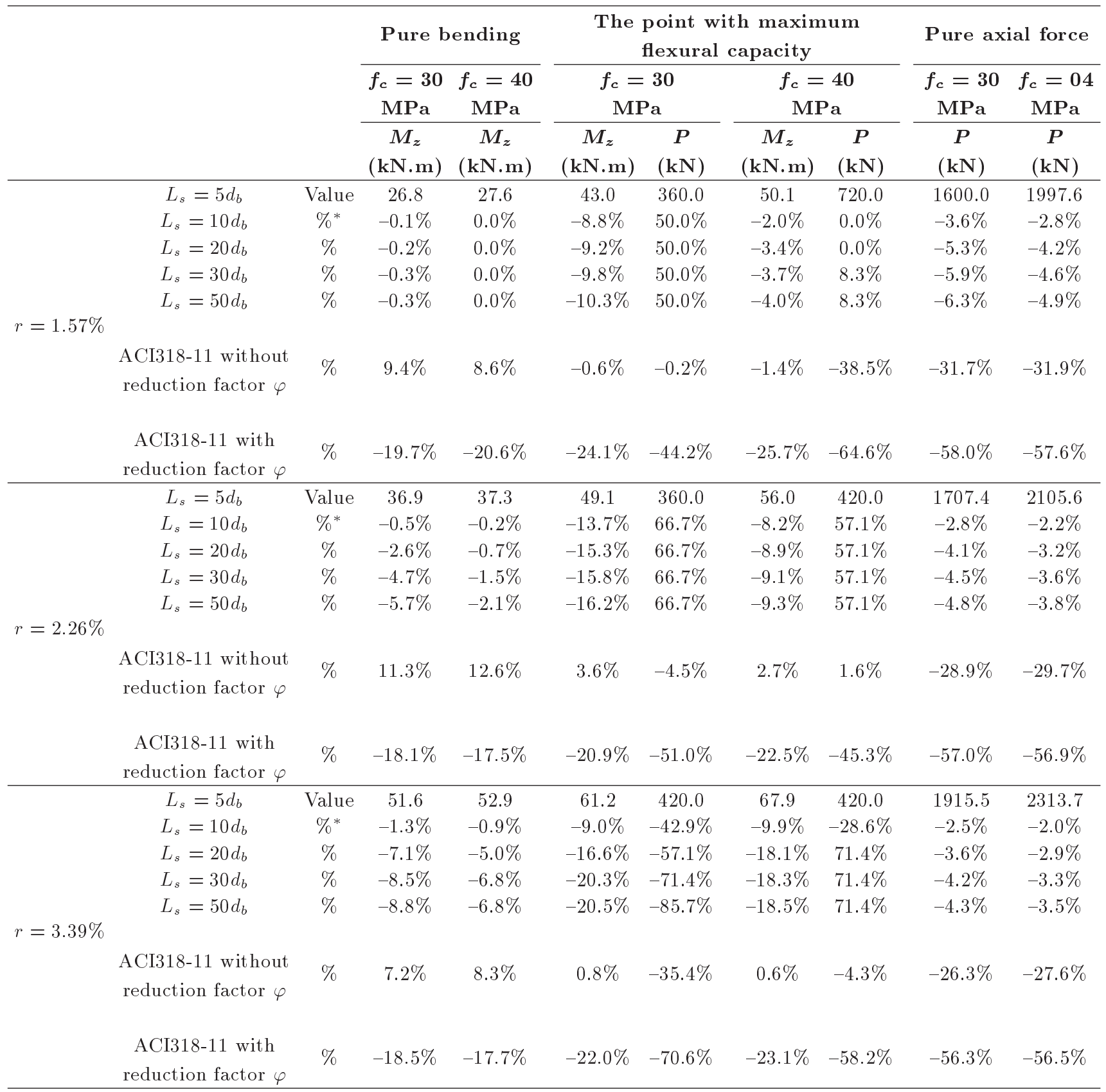

*The positive and negative percentages of differences corresponded to higher and lower values per $L_{s}=5 d_{b}$, respectively.

is assumed to be shorter than $12.5 d_{b}$, separation from the envelope curve is after the yield point. The effect of the second status is normally negligible in capacity and will substantially be reflected in ductility as well as post-yield behavior.

The first status $\left(L_{s}>12.5 d_{b}\right)$, depending on the amount of $L_{s}$, can decrease the yield point and compressive bar capacity and, consequently, reduce the whole capacity of the section. Obviously, this can be true provided that the conditions for buckling of bars are available. Even with large amounts of $L_{s}$, the buckling of longitudinal bars may not occur, because the surrounding concrete of steel bar acts as lateral support. In other words, when the surrounding concrete of compressive steel bars loses strength and is crushed, the buckling needs to be investigated. Generally, it can be claimed that conditions for the buckling of compressive steel bars depend on the amount of $L_{s}$, and the yield strengths of steel bars and their surrounding concrete. Therefore, a prerequisite for the initiation of possible buckling of longitudinal steel bars is that the surrounding concrete loses its resistance. By defining $\varepsilon_{c 0}$ as the strain corresponding to compressive strength of concrete and $\varepsilon_{b}$ as the intersection point between 


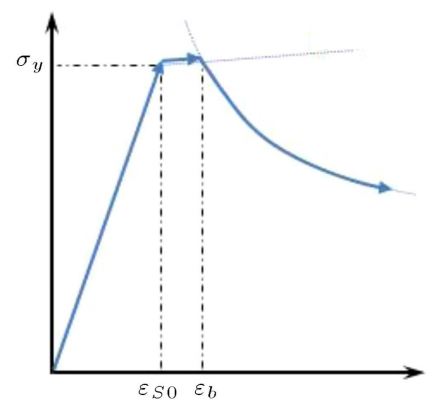

(a)

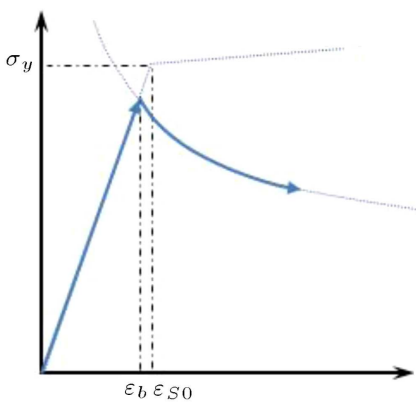

(b)

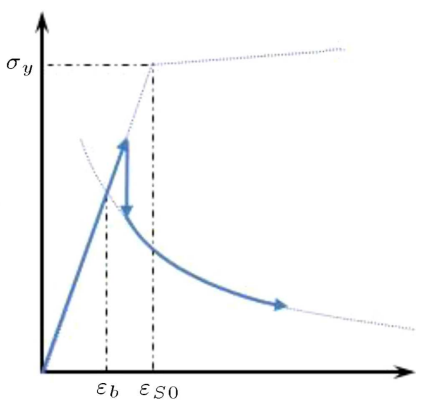

(c)

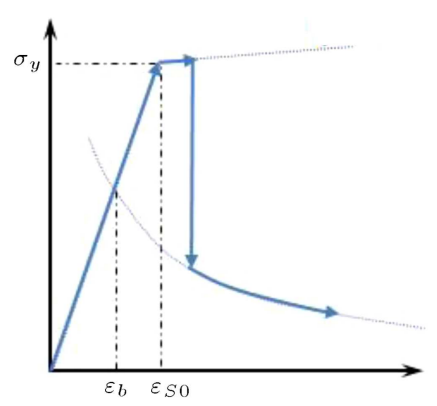

(d)

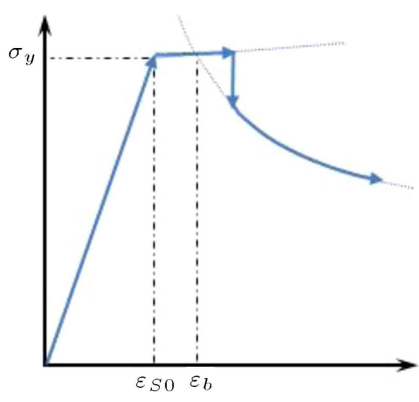

(e)

Figure 12. The behavior of compressive steel bar in different conditions.

the buckling path and the envelope curve of the stressstrain steel bar, one of the following conditions would be dominant:

(a) $\varepsilon_{b}>\varepsilon_{S 0}$ and $\varepsilon_{b}>\varepsilon_{C 0}$ for $L_{s}<0.6 \varepsilon_{S 0}^{-0.5} d_{b}$. The buckling path starts after the yield point of steel bar (Figure 12(a)). Models with $L_{s}=5 d_{b}$ and $10 d_{b}$ are in this situation. Due to the post-yield buckling, $L_{s}$ will just affect the confinement effectiveness factor and, consequently, discrepancy will be observed in capacity values;

(b) $\varepsilon_{b} \leq \varepsilon_{C 0}$ and $\varepsilon_{b}>\varepsilon_{C 0}$ for $0.6 \varepsilon_{S 0}^{-0.5} d_{b} \leq$ $L_{s} \leq 0.6 \varepsilon_{S 0} \varepsilon_{C 0}^{-1.5} d_{b}$. The buckling path starts before the yield point of the steel bar and, finally, the concrete cover is crushed prior to buckling (Figure 12(b)). This state rarely occurs because of the typical values of $\varepsilon_{S 0}$ and $\varepsilon_{C 0}$. The usual value for $\varepsilon_{C 0}$ is more than 0.002 . Moreover, for steel bars with yield points in a range of 400 to $500 \mathrm{MPa}, \varepsilon_{S 0}$ will change between 0.002 and 0.0025 . If $L_{s}$ provides the conditions for the occurrence of this state, drop in the resistance of steel bar would be negligible;

(c) $\varepsilon_{b} \leq \varepsilon_{S 0}$ and $\varepsilon_{b}<\varepsilon_{C 0}$ for $L_{s}>0.6 \varepsilon_{S 0}^{-0.5} d_{b}$. Conditions are available in order to enter the buckling path, which starts before the yield point of steel bar; but, the strength and stability of surrounding concrete do not permit to enter the buckling path. In this status, steel bars tend to return to the buckling path by loading progress, after crushing of the cover concrete. Hence, remarkable decline in resistance can be observed
(Figure 12(c)). Models with $L_{s}=20 d_{b}, 30 d_{b}$, and $50 d_{b}$ show this situation. By increasing values of $L_{s}$, the buckling of steel bars is more likely to take place. However, it will happen after crushing of the concrete cover; thus, the strength limit of compressive steel bars is the same for different values of $L_{s}$. Although, their behavior would be different after crushing of concrete, since by increasing $L_{s}$, the degradation of resistance and prolapse of curve behavior after initiation of buckling increase. Slight differences due to the confining effect are not significant (Figure 13);

(d) $\varepsilon_{b} \leq \varepsilon_{S 0}<\varepsilon_{C 0}$ for $L_{s}>0.6 \varepsilon_{S 0}^{-0.5} d_{b}$. Here, conditions are available to enter the buckling

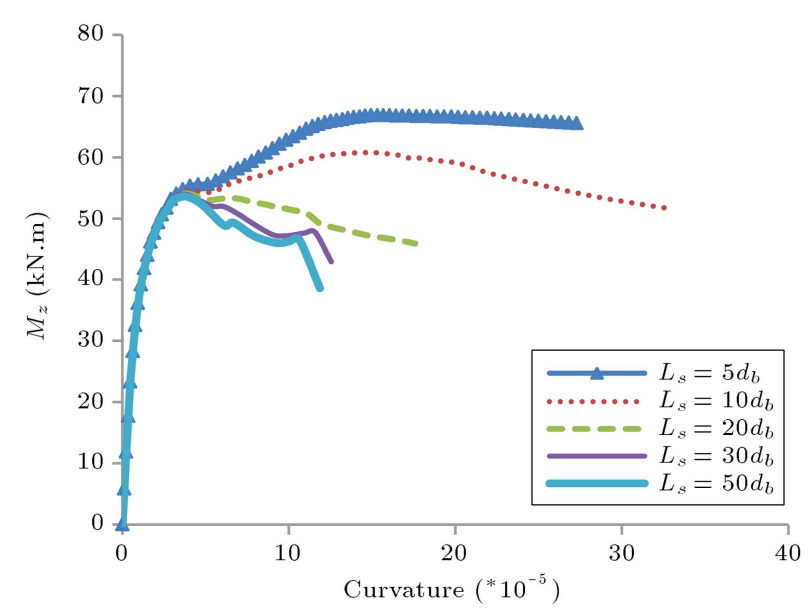

Figure 13. The moment-curvature curve of the specimen S3-2. 
path, which starts before the yield point of steel bars; but, because of the strength of surrounding concrete, buckling does not happen before the crushing of concrete cover (Figure 12(d)). On the other hand, as $\varepsilon_{S 0}<\varepsilon_{C 0}$, compressive steel bar yields before initiation of concrete crushing. Crushing of concrete cover in this situation will lead to a sharp drop in resistance. The behavior is non-ductile; however, steel bar passes the yield stage and, logically, buckling does not interfere with strength capacity of the section, although it affects ductility. This situation is common for steel bars with low yield points. With regards to the usual values of strain corresponding to yield point of concrete and steel bar, this situation is likely to happen when the yield point of steel bar is lower than $400 \mathrm{MPa}$;

(e) $\varepsilon_{S 0}<\varepsilon_{b}<\varepsilon_{C 0}$, which is the fusion of (a) and (d) (Figure 12(e)) and widely overshadows ductility. Slight impact on the strength capacity of section is due to the confinement of concrete rather than buckling.

\section{Conclusions}

- The effect of increasing $L_{s}$ on flexural capacity of RC sections under pure bending is not significant. Changes of $L_{s}$ between $5 d_{b}$ to $50 d_{b}$ leads to reduction, from zero to $9 \%$, in flexural capacity of section. By increasing $\rho$ and $f_{y} / f_{c}$, the compressive steel bar has a more significant role in the strength capacity of section and, consequently, the effect of buckling on capacity would be remarkable. However, by considering the effect of buckling, the value of ultimate strength capacity recommended by ACI code is highly acceptable, which conservatively estimates flexural capacity $17.5 \%$ less than the numerical value;

- The effect of buckling is more significant in estimating the maximum flexural capacity, which is achieved in the presence of axial compressive load. On the other hand, reduction in the capacity due to increase in $L_{s}$ is low because of the prerequisite for buckling, which crushes the surrounding concrete of the steel bars. Among the examined specimens, changes of $L_{s}$ from $5 d_{b}$ to $50 d_{b}$ lead to reduction, from zero to $21 \%$, in flexural capacity. Moreover, the difference is greater by increasing $\rho$ and $f_{y} / f_{c}$. In the presence of buckling effect, the ultimate strength capacity proposed by the code is conservatively acceptable and it approximately estimates the flexural capacity of the section at least $20.9 \%$ less than the numerical capacity;

- In the presence of pure axial force, the section is completely under pressure and the required con- dition for buckling is available, provided that the surrounding concrete is crushed. These conditions will be achieved when the strain in concrete cover exceeds $\varepsilon_{C 0}=0.002$. This situation means that axial force is well tolerated and is away from the possibility of buckling before this strain. If $L_{s}$ increases, the bar experiences this amount of strain before buckling even if $\varepsilon_{b}$ is too lower than the aforementioned value. Changes of $L_{s}$ between $5 d_{b}$ to $50 d_{b}$ results in reduction from zero to $6 \%$ in axial capacity. By increasing $\rho$ and $f_{y} / f_{c}$, differences will be less and more, respectively. The values of nominal and ultimate strength capacity estimated by the code are conservative and at least $26 \%$ and $56 \%$ less than the numerical values estimated with the effect of buckling, respectively;

- Although deterrent restrictions in ACI code for the occurrence of buckling effect are sufficient, if $L_{s}$ is considered to be exceeded, the reduction effects of this factor on ultimate strength capacity are not significant and the estimated capacity with the effect of buckling will not be less than the ultimate strength capacity achieved by the method of ACI code. In other words, ultimate strength capacity with the effect of buckling gained by the ACI code has sufficient factor of safety. However, this factor of safety can just confirm the bearing capacity. Ductility and behavior of column section after crossing the ultimate strength capacity are significantly related to $L_{s}$, which can intensify the possibility of brittle fracture as well as resistance drop ratio.

\section{Acknowledgments}

This research was supported by the grant, code PGU/FE/1-4/1390/1565, of the office of vice president for research at Persian Gulf University. The authors hereby thank them for financial aid.

\section{References}

1. American Concrete Institute, ACI 318-11 Building Code Requirements for Structural Concrete and Commentary, ACI 318R-11, Farmington Hill, MI, USA. (2011)

2. Gomes, A. and Appleton, J. "Nonlinear cyclic stressstrain relationship of reinforcing bars including buckling", Engineering Structures, 19(10), pp. 822-826 (1997). DOI: 10.1016/s0141-0296(97)00166-1

3. Berry, M.P. and Eberhard, M.O. "Practical performance model for bar buckling", Structural Engineering, 131(7), pp. 1060-1070 (2005). DOI: 10.1061/(ASCE)0733-9445(2005)131:7(1060)

4. Bae, S., Mieses, A., and Bayrak, O. "Inelastic buckling of reinforcing bars", Structural Engineering, 131(2), 
pp. 314-321 (2005). DOI: 10.1061/(ASCE)07339445(2005)131:2(314)

5. Zong, Z. and Kunnath. "Buckling of reinforcing bars in concrete structures under seismic loads", The 14th World Conference on Earthquake Engineering, Beijing, China, October, pp. 12-17 (2008).

6. Dhakal, R.P. and Maekawa, K. "Path-dependent cyclic stress-strain relationship of reinforcing bar including buckling", Engineering Structures, 24(11), pp. 13831396 (2002). DOI: 10.1016/SO141-0296(02)00080-9

7. Massone, L.M. and Moroder, D. "Buckling modeling of reinforcing bars with imperfections", Engineering Structures, 31(3), pp. 758-767 (2009). DOI: 10.1016/j.engstruct.2008.11.019.

8. Kashani, M.M., Crewe, A.J., and Alexander, N.A. "Nonlinear stress-strain behavior of corrosiondamaged reinforcing bars including inelastic buckling", Engineering Structures, 48, pp. 417-429 (2013). DOI: 10.1016/j.engstruct.2012.09.034

9. Giuffre, A. and Pinto, P.E. "The behavior of reinforced concrete due to strong intensity of cyclic loads" [Il Comportamento del cemento armato per sollecitazzioni cicliche di forte intensita], Journal of Civil Engineering, Maggio [Giornale Del Genio Civile], Maggio (1970) (In Italian).

10. Lukkunaprasit, P., Tangbunchoo, T., and Rodsin, K., "Enhancement of seismic performance of reinforced concrete columns with buckling-restrained reinforcement", Engineering Structures, 33(12), pp. 3311-3316 (2011). DOI: 10.1016/j.engstruct.2011.08.019.

11. Lopes, A.V., Lopes, S.M.R., and Do Carmo, R.M.F. "Effects of the compressive reinforcement buckling on the ductility of RC beams in bending", Engineering Structures, 37, pp. 17-23 (2012).

12. Potger, G.M., Kawano, A., Griffith, M.C., and Warner, R.F. "Dynamic analysis of RC frames including buckling of longitudinal steel reinforcement", Paper No. 4.12.01, NZSEE 2001 Conference (2001)

13. Monti, G. and Nuti, C. "Nonlinear cyclic behavior of reinforcing bars including buckling", Structural Engineering, ASCE, 118(12), pp. 3268-3284 (1992). DOI: 10.1061/(ASCE)0733-9445(1992)118:12(3268)

14. Watson, S., Zahn, F.A., and Park, R. "Confining reinforcement for concrete columns", Structural Engineering, $A S C E, \mathbf{1 2 0}(6)$, pp. 1798-1824 (1994). DOI: 10.1061/(ASCE)0733-9445(1994)120:6(1798)

15. Sheikh, S.A. and Yeh, C.C. "Tied concrete columns under axial load and flexure", Structural Engineering, ASCE, 116(10), pp. 2780-2800 (1990). DOI: 10.1590/S1679-78252014000700010

16. Papia, M. and Russo, G. "Compressive concrete strain at buckling of longitudinal reinforcements", Structural Engineering, ASCE, 115(2), pp. 382397 (1989). DOI: 10.1061/(ASCE)07339445(1989)115:2(382)

17. Moehle, J.P., Hooper, J.D., and Lubke, C.D. "Seismic design of reinforced concrete special moment frames: a guide for practicing engineers", NEHRP Seismic Design Technical Brief No.1 (2008).
18. Hashemi, S.SH., Tasnimi, A.A., and Soltani, M. "Nonlinear cyclic analysis of reinforced concrete frames, utilizing new joint element", Scientia Iranica, Transaction A, 16(6), pp. 490-501 (2009).

19. Hashemi, S.SH. and Vaghefi, M. "Investigation of the effect of a bar's inadequate embedded length on the P-M interaction curve of reinforced concrete columns with rectangular sections", Turkish Journal of Engineering and Environmental Sciences, 36, pp. 109-119 (2012).

20. MathWorks, MATLAB. "The language of technical computing", Version 7.11.0. (R2010a) (2010).

21. Comite Euro International du Beton. "CEB-FIP model code for concrete structures", Paris (1978).

22. Yassin, M.H.M. "Nonlinear analysis of pre-stressed concrete structures under monotonic and cyclic loads", PhD Thesis, University of California, Berkeley, California (1994).

23. Gan, Y. "Bond stress and slip modeling in nonlinear finite element analysis of reinforced concrete structures", A Thesis Submitted for Degree of Master of Applied Science Graduate, Department of Civil Engineering, University of Toronto (2000).

24. Kostantakopoulos, G. and Bousias, S. "Experimental study of the effect of reinforcement stability on the capacity of reinforced concrete columns", Paper No 770, 13th World Conference on Earthquake Engineering, Vancouver, B.C., Canada, August 1-6 (2004).

25. Qiu, F., Li, W., Pan, P., and Qian, J. "Experimental tests on reinforced concrete columns under biaxial quasi-static loading", Engineering Structures, 24, pp. 419-428 (2002). DOI: 10.1016/s0141-0296(01)00108

26. Mander, J.B., Panthaki, F.D., and Kasalanati, A. "Low-cycle fatigue behavior of reinforcing steel", Journal of Materials in Civil Engineering, 6(4), pp. 453-468 (1994). DOI: 10.1061/(ASCE)0899$1561(1994) 6: 4(453)$

27. Mander, J.B. "Seismic design of bridge piers", $\mathrm{PhD}$ Thesis, University of Canterbury Christchurch, New Zealand (1983).

28. Bai, Y.L., Dai, J.G., and Teng, J.G. "Experimental study on the buckling behavior of reinforcing bars in FRP-confined RC columns", The 15th World Conference on Earthquake Engineering, Lisbon, Portugal (2012).

\section{Biographies}

Seyed Shaker Hashemi was born in Kazeroun, Iran, in 1981. He received a BS degree in Civil Engineering from the Power and Water University of Technology (PWUT) in 2003, and MS and PhD degrees in Earthquake and Structural Engineering from Tarbiat Modares University, Tehran, Iran, in 2005 and 2009, respectively. He is currently Assistant Professor in the Department of Civil Engineering at the Persian Gulf 
University, Bushehr, Iran, and his research interests are in the areas of structural and earthquake engineering, especially nonlinear numerical analysis of reinforced concrete and the design of structures.

Mohammad Vaghefi was born in Shiraz, Iran, in 1973. He received BS and MS degrees in Civil Engineering from Shiraz University, Iran, in 1997 and 1999, respectively, and $\mathrm{PhD}$ degree, in 2009, from Tarbiat Modares University, Tehran, Iran. He is currently Associate Professor of Civil Engineering. He has published about 60 journal papers and presented about 200 papers at national and international conferences.

Mehdi Hemmat was born in Shiraz, Iran, in 1988. He received BS degree in Civil Engineering from Islamic Azad University, Estahban Branch, Fars, Iran, in 2011 and MS degree in Structural Engineering from Persian Gulf University, Bushehr, Iran, in 2013. Currently, he is a member of a structural design firm in Shiraz. Also, he works as a lecturer of Civil Engineering courses at Apadana Educational Institute, Shiraz, Iran. 